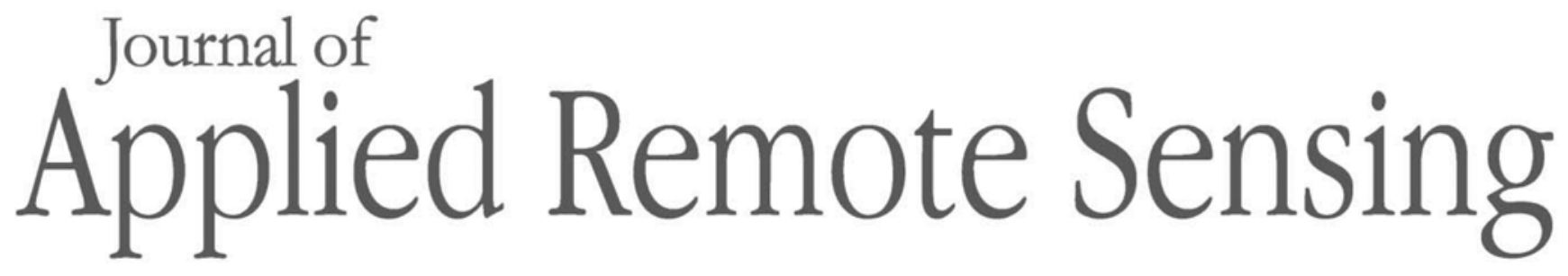

RemoteSensing.SPIEDigitalLibrary.org

\title{
Errata: Remote-sensing application for facilitating land resource assessment and monitoring for utility-scale solar energy development
}

Yuki Hamada

Mark A. Grippo

\section{SPIE.}




\title{
Errata: Remote-sensing application for facilitating land resource assessment and monitoring for utility-scale solar energy development
}

\author{
Yuki Hamada and Mark A. Grippo
}

Argonne National Laboratory, 9700 South Cass Avenue, Argonne, Illinois 60439, United States

[DOI: 10.1117/1.JRS.9.099998]

This article [J. Appl. Remote Sens. 9(1), 097694 (23 June 2015)] contained several errors, explained here. In Sec. 2.3.3, in the first sentence of paragraph 2, the text "red/NIR" has been changed to "green/NIR." Equation (2) has also been changed accordingly. It now reads:

$$
\mathrm{ERI}=\frac{\left[\left(-1.257 \times \frac{\rho_{\text {green }}}{\rho_{\text {red }}}\right)\right]-\frac{\rho_{\text {green }}}{\rho_{\mathrm{NIR}}}+1.698}{\sqrt{-1.257^{2}+1}} .
$$

Finally, the same error has been corrected in Fig. 3 and the corresponding caption. The corrected version is shown here:

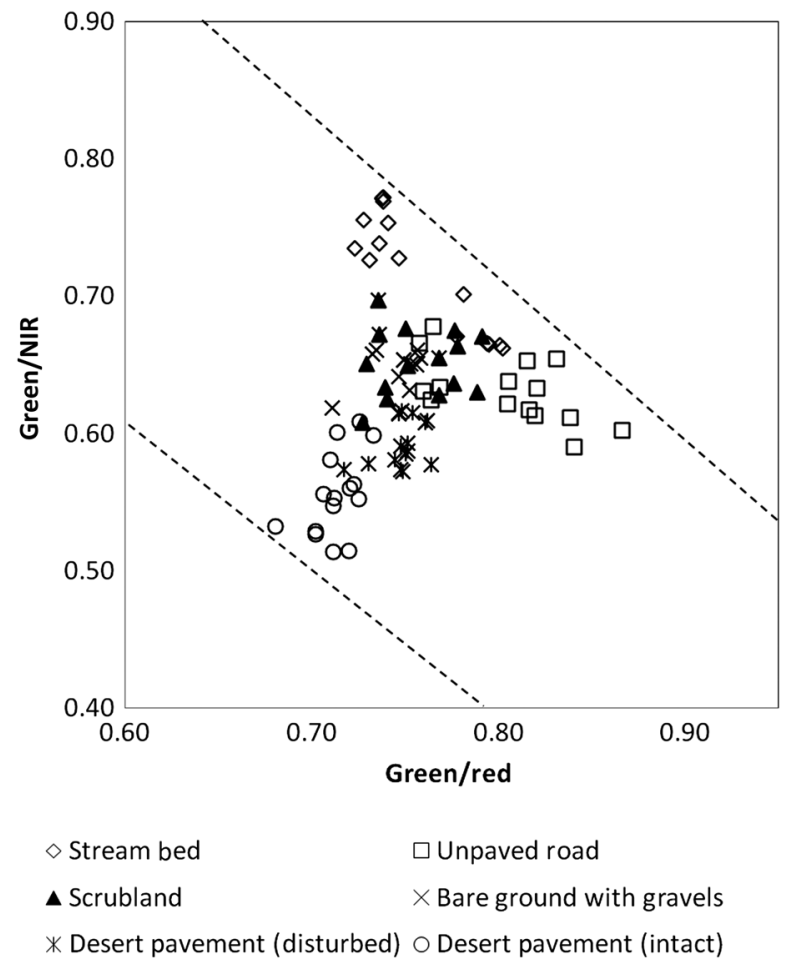

Fig. 3 Scatter plot of a green/red band ratio versus a green/NIR band ratio by surface type for correspondence to a range of erosion risks.

The article was corrected online on 30 June 2015.

() 2015 Society of Photo-Optical Instrumentation Engineers (SPIE) 